\title{
LA ANTROPOTOPONIMIA PREDIAL ROMANA. IMPLICACIONES INTERDISCIPLINARES EN EL ORIGEN DE UN FENÓMENO EUROPEO*
}

\author{
THE ROMAN PREDIAL ANTHROPOTOPONYMY. \\ INTERDISCIPLINARY IMPLICATIONS \\ IN THE ORIGIN OF A EUROPEAN PHENOMENON
}

\author{
Rafael SABIo GonZÁLEZ** \\ Museo Nacional de Arte Romano de Mérida
}

\begin{abstract}
RESUMEN. A través del presente artículo, se pretende mostrar una panorámica sobre los primeros acercamientos por parte de la comunidad científica europea y académicos de muy diferentes disciplinas, a un fenómeno lingüístico muy característico de la cultura romana que entrańa importantes consecuencias a nivel histórico y arqueológico: aquel relacionado con la designación de los predios agrícolas romanos que tomaron su nombre del de sus propietarios o possessores. Si bien se aludirá a su fundamentación en la segunda mitad del siglo xviII, como consecuencia del hallazgo de la Tabula de Veleia, se centrará la atención sobre el análisis del fenómeno por parte de los investigadores italianos, franceses y alemanes, en el periodo comprendido entre el último tercio del siglo XIX y el primer cuarto del siglo xx. Con dicho panorama, se contrastarán los orígenes de los estudios sobre el tipo toponímico en la península ibérica, distinguiéndose ciertos trabajos de ámbito local y autores nacionales de aquellos otros empeños llevados a cabo por lo que podría considerarse una «escuela germánica». Ante tales estudios, se abrirá levemente el marco cronológico para llevarlo hasta la Guerra Civil, aludiéndose puntualmente a su repercusión en ciertas publicaciones posteriores. Finalmente, se ofrecerán una serie de valoraciones y conclusiones generales a la cuestión, en las que se hará un especial hincapié en la naturaleza del fenómeno en sus primeros ańos de desarrollo científico y el singular papel del panorama hispánico.
\end{abstract}

PALABRAS CLAVE: Toponimia, antropotoponimia, onomástica, arqueología, villa romana.

ABSTRACT. The present article aims to show an overview of the first approaches by the European scientific community by scholars from very different disciplines, to a linguistic phenomenon very characteristic of Roman culture that entails important consequences at a historical and archaeological level: the one related to the designation of the Roman agricultural lands that took their name from that of their owners or possessors. Although it will be referred to its foundation in the second half of the 18th century, as a consequence of the discovery of the Tabula de Veleia, attention will be focused on the analysis of the phenomenon by Italian, French and German researchers, in the period between the last third of the 19th century and the first quarter of the 20th century. With this perspective, the origins of studies on the toponymic type in the Iberian Peninsula will be contrasted, distinguishing certain works of local scope and national authors from those other efforts carried out by what could be considered a «Germanic school». In view of such studies, the chronological frame will be slightly opened to take it to the Civil War, punctually alluding to its repercussion in certain later publications. Finally, a series of assessments and general conclusions will be offered to the question, in which special emphasis will be placed on the nature of the phenomenon in its first years of scientific development and the unique role of the Hispanic panorama.

KEYWORDS: Toponymy, anthropotoponymy, onomastics, archaeology, Roman uilla.

* Este trabajo ha sido realizado en el marco del proyecto de investigación MINECO-Ministerio de Economía y Competitividad «Arqueología e Interdisciplinariedad: una investigación arqueológica-histórica sobre las relaciones interdisciplinares en la Historia de la Arqueología espańola (siglos XIX y xx)» (HAR2016-80271-P, IP M. Díaz-Andreu) subvencionado por la AEI/FEDER, UE.

\footnotetext{
** Correspondencia a / Correspondence to: Rafael Sabio González, Museo Nacional de Arte Romano de Mérida (España) - rafael.sabio@cultura. gob.es - http://orcid.org/0000-0003-2370-7511.

Cómo citar / How to cite: Sabio González, Rafael (2020), «La antropotoponimia predial romana. Implicaciones interdisciplinares en el origen de un fenómeno europeo", Veleia, 37, 45-55. (https://doi.org/10.1387/veleia.20968).
}

Recibido: 28 junio 2019; aceptado: 24 noviembre 2019.

ISSN 0213-2095 - elSSN 2444-3565 / (C) 2020 UPV/EHU 


\section{Introducción. Nacimiento y OlVido de Un FENÓMENo SINGULAR DE LA CUltura ROMANA}

Uno de los fenómenos quizá más reconocidos de la cultura romana es el de su fuerte carácter agrario y la elevada organización que alcanzó la explotación del territorio bajo su dominio. Su modelo, además, gracias a la dilatación de las fronteras del Imperio, sería exportado a las diversas provincias del mismo, donde se implementaría con un éxito tal que constituiría un auténtico referente en los tiempos futuros. Hablamos del conocido sistema de fundi y uillae, cuyo ejemplo pudo no solo ser estudiado sino también imitado gracias a su difusión a través de los célebres tratados agrícolas latinos de autores tales como Varrón, Catón, Columela y Palladio, incesantemente copiados e impresos durante la Edad Media y la Edad Moderna respectivamente.

En el ambiente propiciado por el desarrollo de dicho sistema y debido fundamentalmente a la profunda sistematización alcanzada por la propiedad privada en Roma, muchos predios rústicos llegarían a ligarse de tal modo a sus propietarios o possessores, que serían designados por medio de los nombres personales de estos últimos. Dicha relación pudo verse atestiguada a través de la documentación administrativa romana, en muchos casos perdida debido al carácter efímero del soporte que la contuvo. Pero paralelamente, y es lo que nos interesa destacar, también logró perpetuarse de un modo más informal por medio de su implementación geográfica: lo que en filología se conoce con el término de toponimia.

La antropotoponimia o toponimia generada a partir de nombres propios de personas no es un fenómeno originado en la cultura romana, sin lugar a dudas. Sin embargo, sí cabría considerar que lo fuese su extensión a un mayor espectro social, dado que en otras culturas anteriores se ligó fundamentalmente a la designación de entes de cierta categoría a partir de los nombres de los jerarcas implicados en su generación o reforma. Roma fue la responsable, sin duda, de extender su manejo a los terratenientes de los innumerables predios contenidos dentro de las fronteras de su territorio. Bajo el influjo de su modelo agrario, el primer possessor de un fundo, si no un personaje destacado ligado al mismo, motivaría la fijación en el substrato oral de su onomástica en la designación de aquellas tierras que fuesen de su propiedad, cuando no de algún elemento integrado dentro de las mismas, fundamentalmente de naturaleza constructiva, tales como las uillae y los uici.

Un problema, y al tiempo una ventaja de la que cabría definir como antropotoponimia rural o predial romana, es el hecho de que el sentido de muchos de los nombres de lugar ligados a este singular tipo sería prontamente olvidado, pasando a emplearse estos de un modo inercial para la identificación particular de parajes y hábitats humanos. Este proceso debe ser consecuencia de la enorme variedad de la onomástica personal manejada dentro de la cultura latina (incluidos muchos antropónimos ajenos originalmente a la misma), así como del carácter efímero del agente motivante del topónimo (esto es, el possessor responsable de su designación). El olvido de la motivación primigenia de estos topónimos no impediría su perduración. De hecho, el enorme elenco de nombres geográficos susceptibles de emparentarse con la onomástica de possessores latinos en el presente es una buena prueba de ello. Aún es más, dicha incomprensión etimológica ha podido propiciar que en momentos posteriores no se hayan puesto en marcha ciertos mecanismos lingüísticos cuyo manejo se tiene atestiguado ante otros tipos toponímicos, como lo sería el de su traducción o actualización a las diferentes lenguas implementadas en la órbita romana con posterioridad al final de la Antigüedad y hasta el presente. Sin embargo, este aspecto también ha condicionado el que los antropotopónimos prediales romanos hayan sido uno de los últimos tipos en ser reconocidos por la historiografía, tal y como podremos comprobar a través del siguiente apartado.

A lo largo del presente trabajo, abordaremos los agentes implicados en el reconocimiento y estudio del tipo toponímico mencionado, entre finales del siglo XVIII y comienzos del xx. Para ello, 
pondremos especial atención en la distinción de las diferentes disciplinas vinculadas al proceso, tratándose de desentrañar los perfiles investigadores implicados y su singular relación con un fenómeno de profundas connotaciones tanto filológicas como arqueológicas.

\section{EN LOS ORÍGENES DE UN DESCUBRIMIENTO CIENTÍFICO DE RAÍCES INTERDISCIPLINARES}

Tal y como acabamos de mencionar y frente a otros tipos toponímicos, el formado a partir de los nombres de los propietarios agrícolas romanos se vio condicionado por el rápido olvido de su significación, aun dentro de la misma cultura romana, y ello ha derivado sin duda en su tardío descubrimiento. Desde los tiempos del humanismo, ante el creciente interés por la Antigüedad, se fueron publicando y estudiando las diferentes fuentes textuales de la cultura romana que habían logrado subsistir hasta aquel momento, fuese de un modo indirecto, a través de las copias realizadas a lo largo de la Edad Media, o de uno directo, a través fundamentalmente de la epigrafía. Ante este fenómeno, se perciben y enumeran multitud de topónimos, constituyendo una auténtica obsesión del periodo el establecimiento de relaciones entre dichas formas antiguas y las actuales. Por otra parte, entre los topónimos podían distinguirse algunos cuyo ascendente remontaba a las ignotas lenguas prerromanas. Otros, sin embargo, eran más claramente comprensibles para los estudiosos, dado que cabían ser interpretados a partir de las lenguas clásicas, fundamentalmente el latín. Entre estos últimos, se distinguiría ya un nutrido elenco de ejemplos cuya etimología entroncaba con la onomástica de renombrados personajes de la historia romana, tales como generales o emperadores. Mas no sucedería lo mismo con otros supuestos de raíz antroponímica pero una motivación no tan clara, en la mayoría de las ocasiones ni tan siquiera tenidos en cuenta por los estudiosos.

Un hito en la cuestión que nos atañe lo constituiría el descubrimiento en el solar de la antigua ciudad italiana de Veleia, en 1747, de la conocida como Tabula alimentaria traianea. Dicho documento consiste en una inscripción en bronce de enormes dimensiones cuyo texto, uno de las más extensos transmitidos en un soporte epigráfico romano, trata de fijar la obligación de un amplio número de predios agrícolas al pago de unas rentas con destino a la manutención infantil en la península itálica, mediante los intereses de un capital entregado por el fisco a sus propietarios (Blanch Nogués 2015). En su mayor parte, el texto se centra en enumerar los nombres de los fundi comprometidos, junto a la identificación de sus possessores. Y en relación a los primeros, resultaba difícil no distinguir el radical antroponímico de algunos de los topónimos enunciados. De hecho, en el debate científico abierto en los ańos subsiguientes al descubrimiento de la Tabula (Cara de Canonico 1788, De Lama 1819, Desjardins 1854, Pitarelli 1790) parece ser que comenzó a asentarse ya la idea de que los nombres de estos fundos pudiesen haberse formado a partir del de sus possessores. Pero se trata de una cuestión paradójicamente tratada de soslayo, e incluso con precaución, y mientras Cara de Canonico $(1788,20)$ se limita a indicar que la mayoría de los fundi de la Tabula asocian sus designaciones a nombres de familias romanas, transcurridos apenas dos ańos, Pitarelli reconocerá la teoría de algunos «eruditos» que no menciona, por la que el apelativo de algunos predios puede derivar del de un possessor, pero matizando que, de adoptarse sin límite, podría dar lugar a "conjeturas absurdas» (Pitarelli 1790, 48). De cualquier modo, los esfuerzos de los estudiosos del periodo parecerán centrarse en tratar de asociar algunos de los antiguos topónimos prediales con sus presuntos equivalentes actuales.

En 1868, se produjo una circunstancia que podría haber precipitado también el verdadero redescubrimiento y valoración del tipo toponímico que nos atañe. Nos referimos al hallazgo en las proximidades de la localidad gaditana de Sanlúcar de Barrameda de un nuevo epígrafe jurí- 
dico, el conocido como Bronce de Bonanza. En esta ocasión, pese a la casual similitud del soporte con el de la Tabula de Veleia, nos hallaríamos ante un documento de índole privada. El mayor valor del texto, desde nuestra perspectiva, radicaría en que, junto a la alusión a un único fundus, llamado Baianus, figuraría la del propio possessor presuntamente responsable de su designación originaria, Baianius. Hübner, que publicaría la inscripción apenas transcurrido un año de su hallazgo, ya hizo notar la clara relación entre la onomástica de este individuo y la designación de su propiedad (Hübner 1869). Sin embargo, en 1870 se abriría una línea interpretativa que truncaría las consecuencias inmediatas de tal hipótesis, al estimar Mommsen, en su comentario al Corpus Inscriptionum Latinarum de 1870, que debíamos hallarnos ante la consignación de un pacto ideal (apud Bueno Delgado 2004, 156). El epígrafe, según aduce dicho autor, sería empleado así como un mero modelo jurídico, valorando por lo tanto como irreales todos los elementos onomásticos enunciados en el texto, tanto toponímicos como antroponímicos. Tal ha sido el criterio seguido preferentemente ante los reiterados acercamientos al Bronce de Bonanza llevados a cabo desde el campo del Derecho romano.

El estudioso verdaderamente responsable de determinar sistemáticamente la formación de topónimos a partir de los nombres de sus possessores sería el profesor Giovanni Flechia, un renombrado especialista en lingüística histórica o glotología. Su primer acercamiento al tipo toponímico se producirá a consecuencia de un trabajo publicado en 1871 por dicho investigador bajo el título «Di alcune forme de'nomi locali dell'Italia superiore» (Flechia 1871). Aunque el estudio reconoce centrar su atención sobre cuatro sufijos presentes en el norte de Italia, entre ellos el conocido por nosotros como de base -c-, tenderá a referir la latinidad de su uso al demostrar su sistemática aplicación sobre nombres de predios agrícolas denominados a partir de la onomástica de sus propietarios. Tal sufijo, ya con anterioridad, fue reconocido en Suiza y Francia por Gatschet y Quicherat, respectivamente (Gatschet 1867, Quicherat 1867). Tales autores sentarían de hecho las bases sobre el posible origen céltico de la terminación. Sin embargo, y aunque el propio Quicherat admite el empleo del sufijo hasta la Edad Media así como su manejo particular por la lengua latina, nunca llegará a definir su vinculación a la designación de predios rurales por intermediación de su aplicación sobre los nombres de sus possessores romanos (Quicherat 1867). A través de la introducción de su estudio, Flechia reconocerá la importancia constituida por la Tabula de Veleia en la determinación del tipo toponímico (Flechia 1871, 6), empleándola como elemento clave para demostrar la aparición en un documento antiguo de topónimos derivados de nombres de possessores vinculados al mencionado sufijo de base -c-. De igual modo, la Tabula será usada masivamente para ratificar el origen antroponímico de algunos de los casos analizados en relación a la terminación -ago. Desde aproximadamente la mitad del trabajo, se enunciará la asociación de otras terminaciones, como -asco, -ate y -engo, a nombres de antiguos fundos, si bien no exclusivamente a partir de antropónimos latinos, desarrollándose tras el respectivo comentario de cada uno de estos sufijos su correspondiente catálogo de ejemplos vinculados a ellos dentro del área analizada.

El mismo Flechia continuaría en 1874 el abordamiento sistemático de topónimos asociados a nombres de possessores por medio de la publicación de un nuevo trabajo sobre el tema. Su contribución, en esta ocasión, se centraría en la detección de toda una serie de ejemplos vivos pertenecientes a nuestro tipo en el área napolitana (Flechia 1874). Más específicamente, mientras en su anterior trabajo se centraría en rastrear aquellos ejemplos asociados a sufijos de base -c-dentro del ámbito analizado, ahora focalizaría su interés en aquellos otros supuestos dotados de terminaciones de base -n-. Para determinar los antropónimos de origen de cada una de las formas, el investigador acudirá fundamentalmente al nutrido recurso que le ofrecía la epigrafía romana de la región napolitana. En otro orden de cosas, un aspecto a recalcar en dicho trabajo es que a través de una nota marginal a 
su párrafo inicial, enunciaría la representación del tipo toponímico analizado fuera de la propia Italia. Más específicamente, mencionará un corto número de casos tomados tanto del elenco toponímico actual de Francia, como de los supuestos asociables a nombres de possessores dentro del territorio hispano por medio del Itinerario Antonino (Flechia 1874).

Una vez abierta la línea de investigación que nos concierne dentro de la península itálica, la cuestión sería fuertemente retomada por la investigación francesa. El responsable de ello fue Henri Arbois de Jubainville, un destacado historiador, arqueólogo y lingüista que durante el último tercio del siglo xix y los inicios del xx centró su labor en el estudio de la cultura celta. Ello no obstó para que, en un voluminoso trabajo sobre los orígenes de la propiedad rústica en Francia, dedicara una especial atención a una amplia nómina de topónimos derivados a partir de nombres de possessores romanos (Arbois de Jubainville 1890). Para el autor, un auténtico puntal en lo concerniente a los orígenes de nuestro tipo toponímico lo volverá a suponer la mencionada Tabula de Veleia, que aborda a partir del acercamiento que a la misma realizara Desjardins. Por contraste, y pese a que cita su labor esporádicamente, prácticamente parece omitir el referente constituido por Flechia dentro del panorama italiano. La mayor parte de los topónimos analizados por Arbois de Jubainville se vincularían a sufijos de base -c-. Sin embargo y al término de su obra, volverá a dedicar diferentes apartados a aquellos casos en los que percibiese otros tipos de terminaciones. A lo largo de todo este estudio, Arbois de Jubainville desarrollará entradas monográficas para los diferentes supuestos analizados, como ya hiciese Flechia, pero ahondando ahora en cuestiones como la constatación documental medieval de los ejemplos y los referentes antroponímicos de los mismos, que llega a abordar en ocasiones con un detenimiento encomiable.

La labor llevada a cabo por Arbois de Jubainville constituirá el fundamento para la mayoría de los trabajos posteriores sobre el tema. Dentro del propio territorio francés, serían dos investigadores germanos, Skok y Kaspers, los responsables de tomar el relevo en el análisis de la cuestión. Estos se repartirían el territorio objeto de análisis en dos secciones, una correspondiente a su mitad sur y la otra a su mitad norte, abordando el primero el área meridional y el segundo la septentrional para publicar sus correspondientes trabajos (Kaspers 1914, Skok 1906). Ambos autores se centrarán en analizar de un modo ordenado los diferentes topónimos en relación a los respectivos sufijos a los que se asocien. A tal efecto, prestarán una atención prioritaria a los supuestos vinculados a terminaciones de base -c-, como ya hiciera Arbois de Jubainville. Pero a esta añadirán una amplia nómina de ejemplos relacionados con los sufijos de base $-n-\mathrm{y}-s c$-, previamente rastreados en Italia por Flechia. Culminando nuestro recorrido, en Italia, el principal autor en perpetuar en su labor el abordamiento de los nombres de possessores, si bien de un modo no monográfico, sería el glottólogo Silvio Pieri, hallando una especial trascendencia en la transmisión de sus resultados el trabajo que dedicó al análisis de la toponimia en el valle del Arno (Pieri 1919).

\section{El caso español. Entre la innovación y el continuismo}

El origen del estudio de los nombres de possessores en España casi podría considerarse que arranca, al menos desde un plano teórico, con el descubrimiento del conocido como Bronce de Bonanza, en 1868, y su publicación por Hübner el siguiente año. Sin embargo, y tal y como pudimos comprobar, las consideraciones del epigrafista alemán quedarín aisladas, tras abrirse en 1870 la línea interpretativa que pasaría a considerar el relato de la inscripción como un mero supuesto teórico. De cualquier modo, la hipótesis de Hübner no encontraría prácticamente reflejo en la bibliografía ulterior, siendo Menéndez Pidal el único autor que aludiese a la posible asociación del 
fundus Baianus citado en el Bronce de Bonanza con un nombre personal latino de idéntica morfología al segundo elemento del topónimo (Menéndez Pidal 1940, 14). Además, el único objeto que tenía dicho autor a la hora de mencionar el supuesto era el de dar apoyo a la hipótesis antroponímica formulada en torno al origen de la forma Baena, registrada por él en el elenco vigente de las provincias de Córdoba y Murcia. Ni tan siquiera Pabón, al abordar de un modo monográfico la constatación de topónimos asociados a nombres de possessores en Andalucía, aludiría al ejemplo recogido en el antiguo documento epigráfico analizado por Hübner, demostrando la disociación manifiesta entre la arqueología y la lingüística, por una parte, y la epigrafía y el derecho, por otra, en lo que al análisis de tan valioso testimonio se refiere (Pabón 1953).

A partir de este punto, asistiremos, por una parte, a un incipiente acercamiento a la cuestión por parte de estudiosos espańoles de perfiles profesionales e intereses muy variados. Por contraste, a partir del cambio de siglo, se desarrollarán principalmente una serie de estudios por parte de investigadores alemanes que, como Skok y Kaspers en Francia, orientarán sus intereses hacia la lingüística del ámbito hispánico, centrándose de un modo más o menos exclusivo en los topónimos derivados de nombres de possessores. Los referentes de todos estos trabajos se mostrarán difusos, pues mientras que en unas ocasiones los omitirán o carecerán manifiestamente de ellos, en otras se acudirá paradójicamente a Flechia, un autor, como hemos comprobado ya, por lo general obviado en la historia de las investigaciones sobre la cuestión que nos atañe. El único investigador cuya línea se salga de la tendencia general para entroncar principalmente con la bibliografía desarrollada en el ámbito francés será Aebischer, un autor que citará entre sus fuentes de consulta igualmente a una gran parte de los trabajos desarrollados en el ámbito ibérico, tanto por españoles como por extranjeros, tal y como comprobaremos más adelante.

Abordando el panorama recién señalado de un modo más detenido, tras la mencionada adscripción a nuestro tipo del topónimo citado en el Bronce de Bonanza por parte de Hübner, así como tras la configuración de una escueta nómina de ejemplos hispánicos tomados del Itinerario Antonino por parte de Flechia, la siguiente figura que empleará la antropotoponimia rural romana como posible explicación para un nombre de lugar asociado al ámbito hispánico será Vicente Barrantes Moreno, en 1874. Este erudito local, de origen extremeńo y corte autodidacta, tuvo a bien leer ante la Diputación Provincial de Badajoz una memoria final de su primer año como cronista oficial de la provincia. En ella, al tratar el origen del topónimo La Serena, señaló la posibilidad de que derivara de la designación de un amplio predio agrícola, propiedad de una familia romana que indica que podría corresponderse con la mencionada en una inscripción hallada en las termas de Alange. La hipótesis, aunque improbable, tiene el valor de parecer enunciar de un modo espontáneo la derivación de un macrotopónimo hispánico a partir del nombre de un predio agrícola romano, a su vez identificado por medio de la onomástica de su possessor. Además, y como aspecto novedoso, busca el apoyo de un epígrafe del entorno circundante para justificar el étimo propuesto para el caso. De cualquier modo, la Memoria de Barrantes permaneció inédita tras su lectura por espacio de casi 70 años, terminando por publicarse en la Revista de Estudios Extremeńos en 1942, un hecho que justifica su nulo impacto bibliográfico hasta una fecha posterior a la de la edición de dicho volumen (Barrantes Moreno 1942).

En consonancia con el esfuerzo aislado de Barrantes y asociado nuevamente a la región extremeña, un empeño de similares características será el afrontado en el contexto del cambio de siglo por el historiador y arqueólogo Matías Ramón Martínez Martínez. Uno de los proyectos en los que dicho investigador puso una mayor atención, fue en la redacción de una obra sobre la historia del reino de Badajoz durante el periodo islámico, una obra que, sin embargo y debido al temprano fallecimiento de su autor, no pudo ver la luz sino transcurrido un ańo del deceso del mismo, 
en 1905. Tal trabajo, pese a centrarse en la Edad Media, dedicaba un primer capítulo a los antecedentes de la ciudad y su territorio durante la Antigüedad, siendo en tal contexto donde Martínez plantea una interesante hipótesis sobre los orígenes de la actual población. Según dicho autor, al enclave fundado por Ibn Marwan en el siglo ix, le habría antecedido un uicus o aldea de escasa entidad, cuyos orígenes se remontarían al periodo romano. En prueba de ello, argüiría ciertos testimonios arqueológicos. Pero aun antes de exponer estos últimos y por sugerencia de su colega, el arquitecto y también arqueólogo Eduardo Saavedra, haría remontar la designación actual de la urbe a partir del nombre de uno de los primitivos propietarios del referido uicus, que a su entender habría de llamarse Battalius. Aunque no se tiene constancia de la existencia de este antropónimo, Martínez lo colegiría a partir del Battalus testimoniado en una inscripción de Astorga (Martínez Martínez 1905).

Desconocemos el origen de tal hipótesis, pues fuera de la cita de Martínez al testimonio oral de Saavedra, no puede determinarse si este último, o aun el propio Martínez, tendrían constancia de los trabajos desarrollados con anterioridad sobre esta corriente explicativa dentro del ambiente académico europeo, o aún incluso dentro de la península ibérica. La cuestión es que carecemos de referentes a tal planteamiento, así como también de ejemplos de la asunción de dicha interpretación sobre el posible origen del topónimo Badajoz en cualquier estudio posterior sobre el tema, incluidos los recientes diccionarios generales de toponimia espańola llevados a cabo por Nieto Ballester (1997) o Celdrán Gomáriz (2002). Sus postulados únicamente han sido recuperados y analizados precisamente en un artículo llevado a cabo por nosotros en el contexto de la misma línea de investigación que ha motivado el presente trabajo (Sabio González 2018).

El tercer y último hito en la investigación sobre el tema por parte de investigadores españoles, antes de la Guerra Civil, es el acercamiento al mismo por parte de Balari i Jovany dentro del ámbito catalán. La labor llevada a cabo por este insigne filólogo, bajo el título Orígenes históricos de Cataluña, analizará en su primera parte el impacto de la romanización por medio del análisis de un amplio conjunto de topónimos derivados de los nombres de una serie de propietarios de predios rústicos de época romana. El referente expreso del autor será el italiano Flechia y, más concretamente, su primer trabajo sobre la cuestión. Balari i Jovany organizará los diferentes casos en función de las terminaciones que estime percibir en ellos, un dato que le llevará incluso a distinguir entre la población propiamente romana, relacionada con sufijos de base - $n$ - (Balari i Jovany 1899, 6-11), y la que denomina como "galo-romana", asociada a sufijos de base -c- (1899, 11-15). Esta distinción se nutre expresamente del carácter céltico que a este último sufijo le atribuyesen hacia mediados del siglo xIX tanto Gatschet como Quicherat, a quienes cita reiteradamente.

En relación a lo que podríamos considerar como una «escuela germánica», el primer autor que deberíamos tener en cuenta es el propio Hübner quien, pese a abordar frustradamente la cuestión en su estudio sobre el Bronce de Bonanza, retornará sobre el análisis de ciertos casos vinculados a nombres de possessores a través de un artículo publicado en 1900. En esta ocasión y sirviéndose de un trabajo inédito de Manuel Gómez Moreno, el epigrafista alemán se aproximará a una serie de enclaves agrí́colas figurados en las ánforas halladas en el Monte Testaccio de Roma, para tratar de relacionar sus designaciones con ciertos nombres de lugar preservados en el elenco toponímico vigente. Este innovador artículo abrirá la brecha continuada en fecha más reciente por Chic García (1988) y Correa Rodríguez (2016), por la que se analizarán con acierto como derivados de la onomástica de los propietarios agrícolas romanos una nutrida nómina de nombres de predios tomados de la rica epigrafía anfórica de origen bético.

$\mathrm{Al}$ trabajo de Hübner le seguirá en el tiempo un opúsculo publicado por Johannes Jungfer en alemán, en torno a la antropotoponimia en Espańa y Portugal (Jungfer 1902). La perspectiva de 
esta breve contribución resulta muy amplia, tanto conceptual como cronológicamente. Su valor en torno a la cuestión que nos atañe es que, junto a ciertos casos derivados de nombres de generales y emperadores romanos, volverán a hacer su aparición ciertos ejemplos asociados a nuestro tipo, muchos de ellos inéditos hasta el momento. Además, la distribución geográfica de los supuestos analizados resulta bastante equilibrada, en especial si se compara con la ofrecida por los estudios publicados en los años subsiguientes.

Un hito en el análisis de la cuestión que nos atañe, sobre todo por su citación en los trabajos ulteriores, lo constituirá la labor de Wilhelm Meyer-Lübke. Si bien ninguno de los trabajos de este lingüista suizo se centrará expresamente en los topónimos derivados de nombres de possessores, estos encontrarán un especial protagonismo en dos artículos y una monografía publicados por el autor. El primero de estos estudios, que vio la luz en 1923, se centraba en el análisis de los nombres de lugar contenidos en la documentación de la diócesis de Urgell, muchos de los cuales escondían radicales en los que aún resultaban fáciles de distinguir los antropónimos latinos que hubieron de darles origen. A los dos ańos, un segundo artículo de Meyer-Lübke abordará una serie de sufijos de origen prerromano asociados a las lenguas prerromanas hispanas. Aunque duramente criticado con posterioridad, el artículo tiene el mérito de intercalar una serie de ejemplos dotados de terminaciones en -en, -ena que, antes que a un origen previo, el autor prefiere asociar a nombres de possessores latinos, explicando la singular apertura del sufijo en base al posible cierre de una /a/ originaria como fruto de su paso por la lengua árabe. Finalmente, aludiremos a la gran monografía del germano en torno a los orígenes de la lengua catalana, donde recogerá una amplísima nómina de antropotopónimos rurales romanos.

Quizá, una cuestión criticable en el trabajo de Meyer-Lübke es que, más allá de centrarse en el área nororiental de España, llegaría a afirmar que el tipo que nos atañe apenas se conserva en otros puntos de la península ibérica, cuando por trabajos tanto previos como ulteriores, sabemos que no es así. Además, otro de los grandes problemas de su labor es la ausencia de referentes bibliográficos expresos. De cualquier modo, parece dar la impresión de que el autor nunca hubiese tomado en consideración cualquiera de los múltiples estudios llevados a cabo hasta la fecha dentro del ámbito hispánico, lo que explicaría parte de sus conclusiones.

El investigador con el que cerraríamos el periodo analizado sería el cuarto de los autores de origen germánico a los que nos estamos refiriendo: Paul Aebischer. Uno de los primeros trabajos llevados a cabo por este filólogo, se centraría en la toponimia adscrita nuevamente al ámbito catalán. Sin embargo, y pese al título generalista de su obra, Études de toponymie catalane (Aebischer 1926), el autor se centrará de un modo monográfico en el tipo toponímico que aquí nos concierne, ordenando los diferentes supuestos analizados en atención a su asociación a los sufijos -anum, -acum y -ascum. Aunque concisa, la bibliografía indicada al comienzo de la obra expone con claridad sus referentes, tanto europeos en general como hispánicos en particular. Entre los primeros, se cita de un modo expreso a Arbois de Jubainville, así como a Kaspers (1914) y a Pieri (1898; 1919). Respecto a los segundos, alude a Balari i Jovany (1899), así como a Jungfer (1902) y, de Meyer-Lübke (1925a), en especial su artículo sobre la documentación de la Diócesis de Urgell (Meyer-Lübke 1925b). Aunque se trate del panorama bibliográfico más completo de los publicados hasta la fecha, así como un auténtico punto de partida para los ulteriores trabajos sobre el tema (gran parte de los títulos coincidirán con los recogidos por Menéndez Pidal en 1940), no dejan de sorprender algunas ausencias. En especial, recalcaremos la de Flechia, de hecho prácticamente olvidado hasta la actualidad en la bibliografía española sobre toponimia. Pero también haremos notar otras como la de Skok (1906). Por contraste, menos nos sorprende la omisión de ciertas aportaciones quizá no tan relacionadas directamente con el contexto anali- 
zado (Hübner 1869; 1900, Martínez Martínez 1905) o ni tan siquiera publicadas hasta muchos años después (Barrantes Moreno 1942).

Al término de la Guerra Civil, la cuestión volverá a ser prontamente retomada. No obstante, y frente a la aparente continuación de la que hemos denominado como "escuela germánica» por parte de Joseph María Piel (1947) y Gerhard Rohlfs (1951; 1961), serán los investigadores españoles, encabezados por Ramón Menéndez Pidal, quienes tomen el relevo en el análisis de la cuestión dentro del panorama nacional. Además, al perfil filológico del investigador del periodo previo se irán añadiendo otros distintos, fundamentalmente vinculados a las disciplinas históricas, que arrojarán nuevas perspectivas sobre el tema.

\section{Consideraciones finales}

En base a lo expuesto a lo largo de las líneas precedentes, podemos determinar tres valoraciones globales acerca del desarrollo de los estudios sobre la cuestión analizada. La primera valoración incidiría en el hecho de que los más tempranos estudios sobre los topónimos derivados de nombres de possessores nacen en Italia a consecuencia del hallazgo casual de un sorprendente testimonio epigráfico: la conocida como Tabula de Veleia. Paralelamente, se desarrollan en Francia y Suiza ciertos estudios lingüísticos en torno al sufijo -acum o de base -c-. Sin embargo, la verdadera piedra angular en los orígenes del estudio del tipo debe fijarse ante la confluencia del análisis contrastado de ambas cuestiones por parte del incipiente trabajo publicado por el especialista en lingüística histórica o glotología Flechia en 1871. De ahí se dará paso ya a la labor del renombrado historiador Arbois de Jubainville, así como a la creación de una suerte de escuela germánica de filólogos en torno al análisis de la cuestión, que centrará sus esfuerzos en el ámbito francés e hispano. Resulta interesante destacar, en referencia a este panorama, que el ámbito geográfico de estudio del fenómeno parecerá mantenerse constreñido hasta la actualidad a aquel perfilado en estos momentos, no extendiéndose hacia otras áreas romanizadas, como Inglaterra, el norte de África o las provincias orientales.

La segunda valoración, en relación al contexto hispano en particular, es el aparente surgimiento espontáneo de la idea en ciertos trabajos, muy tempranos, relacionados con una serie de casos particulares sitos en el sudoeste peninsular. La aportación de tales estudios tiene el valor de hallarse planteada por profesionales de perfil arqueológico que emplean el tipo toponímico, de un modo casi intuitivo, para suplir el silencio de las fuentes clásicas ante el origen de determinadas entidades o asentamientos de carácter rural.

La tercera valoración enfatizaría la ruptura de la línea recién aludida en torno a los inicios del siglo Xx, para darse paso a una concentración de los esfuerzos en el nordeste peninsular, fundamentalmente de la mano de filólogos germanos vinculados a las corrientes metodológicas europeas desarrolladas en torno a la cuestión que nos atañe. La mera sistematización del rastreo y organización de los casos por medio de los sufijos asociados a los mismos es una buena prueba de su referente, pero también el enorme peso que se le concede a la consignación de las formas que los topónimos manifiesten en sus más tempranos registros, a través de la documentación medieval.

Como conclusión final, ahondando en las relaciones interdisciplinares implicadas en el origen y desarrollo del tipo toponímico relacionado con los nombres de los propietarios de los antiguos predios agrícolas romanos, debemos señalar que la arqueología pareció tener un papel fundamental indirecto en su mismo reconocimiento por la historiografía moderna, dado que fue el hallazgo de ciertos documentos epigráficos, fundamentalmente la Tabula de Veleia, lo que motivó su primer impulso. De igual modo, la lectura y análisis de dichos documentos por parte de los epigrafistas 
condicionaría necesariamente el asentamiento de los postulados posteriores sobre el tipo. Sin embargo y al margen de ciertos empeños puntuales, a partir de Flechia la cuestión pasaría a ser abordada de un modo cada vez más exclusivo por parte de filólogos que irán centrando sus esfuerzos paulatinamente en el elenco toponímico vivo, así como en los documentos que testimonian la presencia particular de los casos en la documentación medieval.

En síntesis, las diferentes disciplinas implicadas en el surgimiento de la antropotoponimia predial romana fueron, por este orden, la arqueología, la epigrafía, la filología, la glotología, la toponomástica, la historia y la paleografía. Algunas de estas disciplinas llegaron a interrelacionar entre sí, pero fundamentalmente a partir de su dominio por un mismo investigador, no por la fluida comunicación entre distintos profesionales. Estos últimos, a su vez, tendían inicialmente a vincularse a las naciones cuyo territorio se analizaba, caso de Flechia y Pieri en Italia, Arbois de Jubainville en Francia o Balari i Jovany y Martínez en España. Sin embargo, una excepción a lo dicho la constituirá lo que hemos venido a denominar como «escuela germánica», integrada por diferentes profesionales de perfil filológico y en menor medida paleográfico, activos en Francia y España durante el primer cuarto del siglo XX.

En este contexto, como podemos comprobar, el papel de la arqueología se irá limitando paulatinamente a sacar a la luz diferentes testimonios documentales que servirán de nutriente para el abordamiento de nuestro tipo toponímico a partir de un perfil más bien lingüístico, aportándole bien nóminas de topónimos derivados de predios agrícolas bien, con posterioridad, nombres personales con los que justificar dichos topónimos. Solo ciertos empeños hispanos preconizarán el valor bidireccional que el estudio de las designaciones de los antiguos fundi tendrá entre las disciplinas arqueológicas e históricas por una parte, y filológicas por otra. A tal efecto, subrayaremos el papel de una personalidad como la de Martínez, personaje de perfil polifacético, que aunó en su efímera trayectoria conocimientos tanto lingüísticos como históricos e incluso manifiestamente arqueológicos, alcanzando en la introducción de su trabajo sobre Badajoz ciertas conclusiones sobre la cuestión insólitas para la época.

Solo llegado el último tercio del siglo xx, comienza a redescubrirse el valor del tipo toponímico por parte de las disciplinas más netamente históricas, resultando relevantes, dentro del caso hispano, los empeños que desde el ámbito de la epigrafía anfórica irían abordándose ya desde los años 80 , así como la publicación de una serie de trabajos en los que se valora de un modo cada vez mayor la importancia que los topónimos derivados de nombres de possessores entrańan ante el correcto análisis de la evolución de los asentamientos rurales romanos (Sabio González, en prensa)

\section{BibLIOGRAFíA}

Aebischer, P., 1926, Études de toponymie catalane, Barcelona: Institut d'Estudis Catalans.

Arbois de Jubainville, H., 1890, Recherches sur l'origine de la propriété foncière et des noms de lieux habités en France (période celtique et période romaine), Paris: Ernest Thorin.

Balari I Jovany, J., 1899, Orígenes históricos de Cataluña, Barcelona: Hijos de Jaime Jepús.

Barrantes Moreno, V., 1942, «Apuntes biográficos: "memoria" original de Vicente Barrantes», Revista de Estudios Extremeños XVI: 141-164.

Blanch Nogués, J. M., 2015, «Acerca de las obligationes praediorum en la Tabula de Veleia», Revista General de Derecho Romano 25, 157-171.

Bueno Delgado, J. A., 2004, «El bronce de Bonanza», Anuario de la Facultad de Derecho de la Universidad de Alcalá 2003-2004, 154-165. 
Cara de Canonico, A. G., 1788, Dei paghi dell'agro Veleiate nominati nella tavola traiana alimentaria, Vercelli: Tipografia Patria.

Celdrán Gomáriz, P., 2002, Diccionario de topónimos españoles y sus gentilicios, Madrid: Espasa.

Correa Rodríguez, J. A., 2016, Toponimia antigua de Andalucía, Sevilla: Universidad de Sevilla.

Chic García, G., 1988, Epigrafía anfórica de la Bética, vol. II. Los rótulos pintados sobre las ánforas olearias. Consideraciones sobre la Annona, Sevilla: Universidad de Sevilla.

De Lama, P., 1819, Tavola alimentaria Velejate detta Trajana, Parma: Carmignani.

Desjardins, 1854, De Tabulis Alimentariis, Paris: Augustus Durand.

Flechia, G., 1871, Di alcune forme de'nomi locali dell'Italia superiore, Torino: Stamperia Reale.

Flechia, G., 1874, Nomi locali del Napolitano derivati da gentilizi italici, Torino: Arnaldo Forni.

Gatschet, A. S., 1867, Ortsetymologische Forschungen als Beiträge zu einer Toponomastik der Schweiz, Berna: Haller.

Hübner, E., 1869, «Ein Pactum Fiduciae», Hermes 3, 283-289.

HüBner, E., 1900, «Nuevas observaciones sobre la geografía antigua de España», Boletín de la Real Academia de la Historia XXXVI, 402-408.

Jungfer, J., 1902, Über Personennamen in den Ortsnamen Spaniens und Portugals, Berlin: Gaertners.

Kaspers, W., 1914, Die mit den Suffixen -acum, -anum, -ascum und-uscum gebildeten Nordfranzösischen Ortsnamen lateinischer Herkunft, Halle: Ehrhardt Karras.

Martínez Martínez, M. R., 1905, Historia del Reino de Badajoz durante la dominación musulmana, Badajoz: Antonio Arqueros.

MenÉndez Pidal, R., 1940, «El sufijo -en, su difusión en la onomástica hispana», Emerita VIII, 1-36.

Meyer-Lübke, W., 1925a, Das Katalanische: seine Stellung zum Spanischen und Provenzalischen, Heidelberg: Carl Winter.

Meyer-LüBKe, W., 1925b, «Zur Kenntnis der vorrömischen Ortsnamen der iberischen Halbinsel», Homenaje ofrecido a Menéndez Pidal, I, Madrid: Hernando: 63-84.

Nieto Ballester, E., 1997, Breve diccionario de topónimos españoles, Madrid: Alianza.

Pabón, J. M., 1953, «Sobre los nombres de la Villa romana en Andalucía», Estudios dedicados a Don Ramón Menéndez Pidal, IV, Cáceres.

Piel, J. M., 1947, «Nomes de possessores latino-cristãos na toponimia asturo-galego-portuguesa», Biblos XXIII, $143-202$ y 283-407.

PIERI, S., 1898, Toponomastica delle Valli del Serchio e della Lima, Torino: Loescher.

PIERI, S., 1919, Toponomastica della Valle dell'Arno, Roma: R. Accademia dei Lincei.

Pitarelli, S. G., 1790, Della celebratissima Tavola Alimentaria di Trajano, Torino: Reale Stamperia di Torino.

Quicherat, J., 1867, De la formation française des anciens noms de lieu, Paris: A. Franck.

Rohlfs, G., 1951, "Aspectos de toponimia española», Boletim de Filología XII, 228-264.

Rohlfs, G., 1961, "Antroponimia e toponomastica», Revue de linguistique romane XXV, 354-368.

Sabio González, R., 2018, "Matías Ramón Martínez y el nombre de Badajoz. Su fundamentación histórico-arqueológica a partir de un nuevo tipo toponímico», Revista de Estudios Extremeños LXXIV (2), 853880.

Sabio González, R., en prensa, «Propietarios, Villas, Toponimia y Arqueología. Desarrollo y Fundamentos de un Fenómeno pluridisciplinar en España», Congreso Internacional Las Villas Romanas Bajoimperiales de Hispania.

Sкок, P., 1906, Die mit den Suffixen -acum, -anum, -ascum und-uscum gebildeten Südfranzösischen Ortsnamen, Halle: Niemeyer. 